\title{
УСТОЙЧИВОЕ РАЗВИТИЕ ЖЕЛЕЗНОДОРОЖНОГО ТРАНСПОРТА: ТЕНДЕНЦИИ, ПЕРСПЕКТИВЫ, НОВЫЕ ПРОЕКТЫ
}

\author{
(c) 2019 Гулый Илья Михайлович \\ кандидат экономических наук, доцент \\ Петербургский государственный университет путей сообщения Императора Александра I, \\ Россия, Санкт-Петербург \\ E-mail: ilya.guliy@mail.ru \\ (c) 2019 Сакс Надежда Вячеславовна \\ кандидат экономических наук, доцент \\ Петербургский государственный университет путей сообщения Императора Александра I, \\ Россия, Санкт-Петербург \\ E-mail: sax-nad@yandex.ru
}

В статье проводится оценка устойчивости железнодорожного транспорта. В основу исследования положена методология оценки статистических показателей функционирования транспортной системы, сгруппированных в блоки: экономические, социальные и экологические. Предложено понятие устойчивости транспортной системы. Выявлены тенденции снижения показателей устойчивости железнодорожного транспорта, что является следствием ухудшения показателей в области экономики. Проведенный анализ должен способствовать принятию последующих управленческих решений, включения необходимых показателей устойчивости железнодорожного транспорта в программные и плановые документы стратегического планирования.

Ключевые слова: устойчивое развитие, устойчивость транспортной системы; индикаторы устойчивости, цифровизация железнодорожного транспорта.

Под устойчивостью транспортной системы авторами понимается ее способность стабильно функционировать и развиваться в течение длительного временного периода в условиях быстро меняющихся условий внутренней и внешней среды, достигая цели своего развития. К таким целям следует отнести: обеспечение удовлетворения потребностей в качественных и безопасных перевозках в соответствии с требованиями населения и экономики, а также тенденциями мирового научно-технического прогресса; приведение в соответствие технико-технологического и ресурсного потенциала транспорта с запросами со стороны национальных и международных потребителей; реализация запросов граждан и экономических субъектов в области транспортной мобильности.

В качестве критериев устойчивости транспортной системы, основываясь на результатах исследований $[1,2,3,5]$, авторами выбраны следующие показатели (табл. 1).

1 группа показателей «Экономическая устойчивость»: динамика грузооборота, пассажирооборота; уровень и динамика производительности труда; уровень и динамика показателей рентабельности перевозок; уровень и динамика фондоотдачи основного капитала; уровень и динамика инвестиций в основной капитал, ввода в действие новых мощностей на транспорте, степени износа основных фондов.

2 группа показателей «Социальная устойчивость»: состояние трудовых ресурсов - динамика подготовки специалистов для отрасли; уровень жизни работников.

3 группа показателей «Экологическая устойчивость»: уровень и динамика выбросов загрязняющих веществ; уровень и динамика образования отходов производства от деятельности транспорта.

Для оценки уровня устойчивости транспортной системы по каждому из приведенных показателей, необходимо учесть степень их близости к наиболее оптимальным значениям, лучшим значениям соответствующих индикаторов по национальной и мировой экономике. Поэтому значение соответствующих показателей выражаются в долях от показателей-эталонов по формуле:

$\mathrm{ki}=\mathrm{xi} / \max (\mathrm{xi})-$ для прямых показателей; $\mathrm{ki}=\min (\mathrm{xi}) / \mathrm{xi}-$ для обратных показателей, для 
которых рост и превышение над эталоном ухудшают состояние устойчивости, хі - значение показателя і в конкретный временной период для оцениваемой транспортной системы; $\max (x i)$ и $\min (x i)$ - значения показателей-эталонов, в качестве которых принимаются пороговые, оптимальные значения.

В каждой из трех групп показателей (экономическая, социальная и экологическая устойчивость) значения различных показателей усредняются. Расчет средний групповых значений проводится по формуле:

$$
\text { Іэкон }(\text { соц., экол. })=\sqrt[n]{\mathrm{kil} \cdot \mathrm{ki} 2 \cdot \mathrm{ki} 3 \cdot \ldots},
$$

где $\mathrm{n}$ - число показателей устойчивости в соответствующей группе экономических, социальных, экологических показателей; ki1, ki2, ki3 и т.д.- выраженные в долях единицы значения показателей устойчивости транспортной систе- мы за конкретный временной период.

Интегральный индекс устойчивости транспортной системы определим по формуле:

$$
\text { Іуст }=\sqrt[3]{\text { Іэкон } \cdot \text { Ісоц } \cdot \text { Іэкол }}
$$

После проведения расчетов необходимо интерпретировать результаты устойчивости транспортной системы. Основываясь на исследовании [5], приведем пороговые значения интегрального индекса устойчивости транспортной системы (таблица 1).

На рисунке 1 приведена динамика показателей деятельности железнодорожного транспорта. Высокой степенью устойчивости характеризуется сектор грузовых железнодорожных перевозок. За последние годы темпы его развития в России выше мировых. Сектор также развивался динамичнее, чем транспортная отрасль по стране в целом.

Таблица 1. Интерпретация пороговых значений интегрального индекса устойчивости транспортной системы [5]

\begin{tabular}{|c|c|}
\hline $\begin{array}{c}\text { Значения интегрального индекса } \\
\text { устойчивости в интервале }\end{array}$ & Степень устойчивости транспортной системы \\
\hline $0,9<$ Іуст $\leq 1,0$ & Высокий уровень устойчивости \\
\hline $0,75<$ Іуст $\leq 0,9$ & Устойчивое развитие \\
\hline $0,5<$ Іуст $\leq 0,75$ & Развитие, близкое к устойчивому \\
\hline $0,25<$ Іуст $\leq 0,5$ & Развитие с определенными признаками устойчивости \\
\hline $0,1<$ Іуст $\leq 0,25$ & Неустойчивое, предкризисное развитие \\
\hline $0 \leq$ Іуст $\leq 0,1$ & Кризисное, абсолютно не устойчивое развитие \\
\hline
\end{tabular}

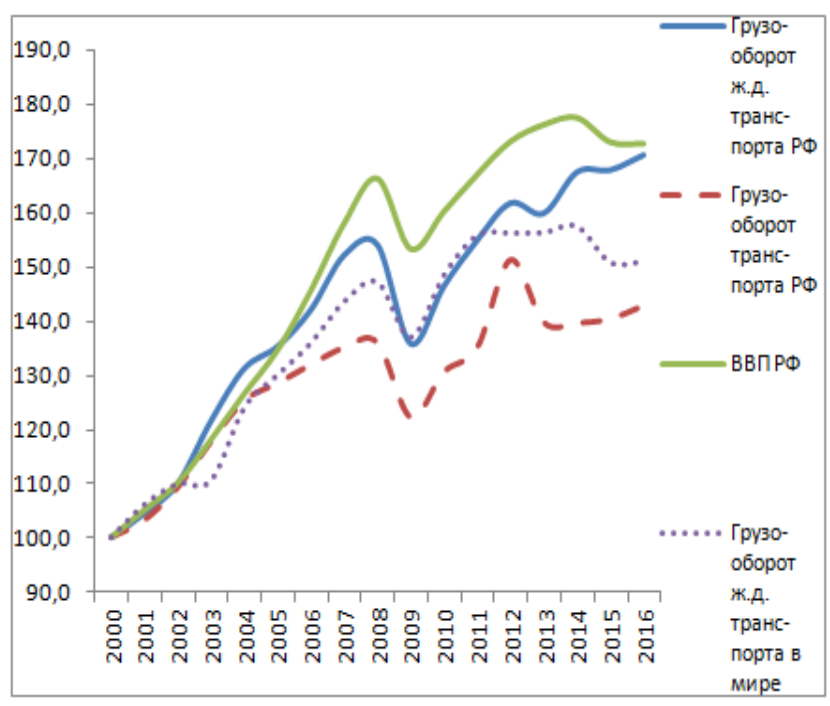

a

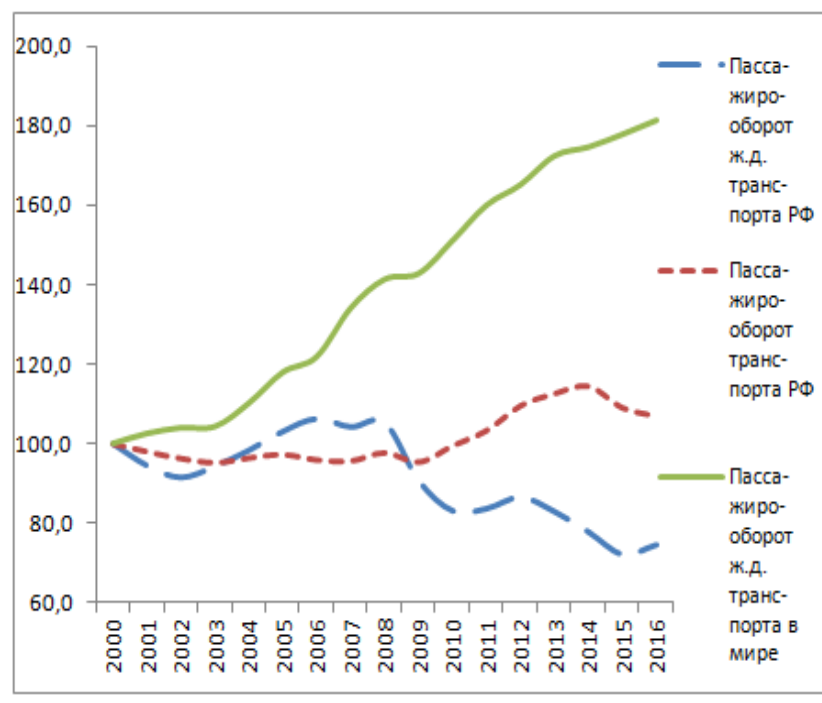

6

Puc. 1 - Динамика грузооборота (а) и пассажирооборота (б) железнодорожного транспорта РФ и сопоставимых показателей для сравнения (2000 год $=100 \%)$

Источник: здесь и далее диаграммы построены на основе расчетов авторов по официальным статистическим данным [4]. 
Железнодорожный пассажирский комплекс отличается неустойчивым развитием: снижение пассажирооборота за рассмотренный период составило 25\%, при этом, прирост пассажирооборота по странам мира в целом составил свыше $80 \%$.

Оценка показателей инвестиционной активности по ряду показателей позволяет заключить, что развитие системы в целом устойчиво, но с 2010 года состояние устойчивости с позиций инвестирования ухудшается (рис. 2). Объем инвестиций на 1 работающего по железнодорожным перевозкам выше, чем в целом по стране почти в 2 раза (рис. 3).

Лучшие периоды инвестиционной активности национального железнодорожного комплекса - 2008-2012 гг. Тем не менее, темпы роста инвестиций в развитие железнодорожных перевозок за весь период ниже, чем по стране и в целом по транспортной отрасли. Ввод но-

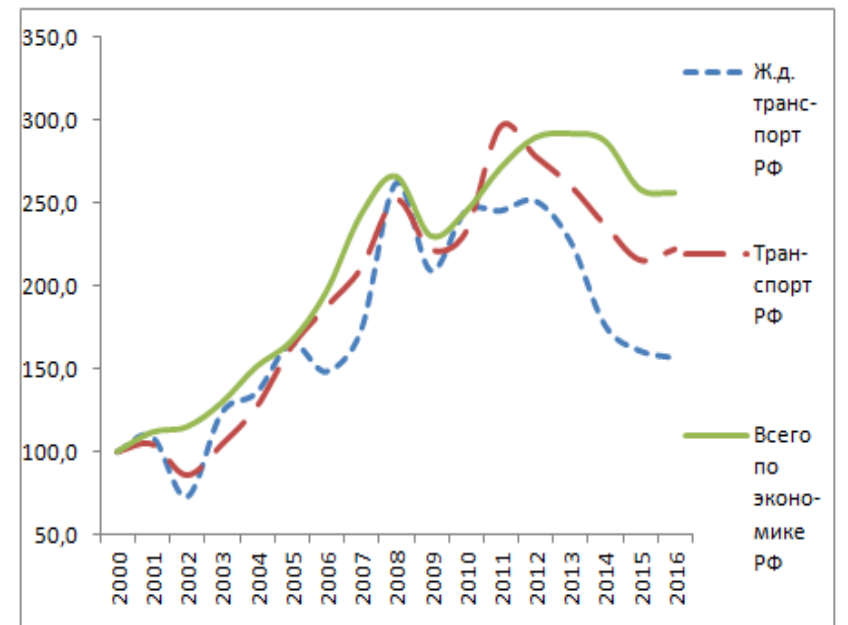

Puc. 2. Динамика инвестиций в основной капитал $(2000$ г. $=100 \%)$

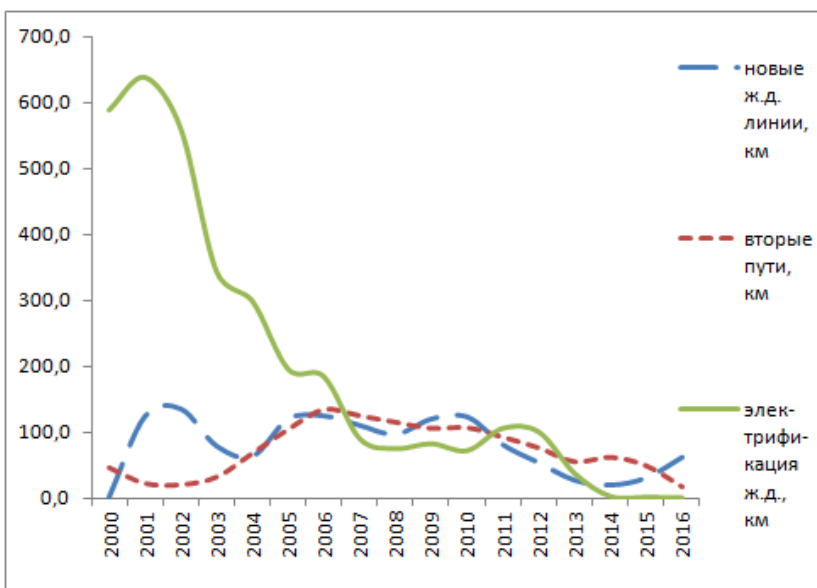

Puc. 4. Динамика ввода новых мощностей ж.д. транспорта, км вых мощностей инфраструктуры был более существенным в начале 2000-х годов (рис. 4). Пик ввода новых железнодорожных путей приходился на 2004-2008 гг. (в среднем за год 105 км), на этот же период - максимальные объемы ввода вторых путей (в среднем 110 км в год), наивысшие темпы электрификации достигнуты в 2000-2003 гг. (порядка 530 км в год).

Далее рассматриваются финансовые показатели устойчивости. По показателю рентабельности продаж, устойчивость ж.д. транспорта не существенная. Ежегодно уровень рентабельности ниже, чем по экономике в целом (рис. 7). С 2013 года рентабельность перевозок падает, уступает средним значениям по транспорту. В 2014 году отмечен отрицательный финансовый результат. Недостаточная устойчивость отмечается в отношении производительности труда. С 2009 года наблюдается растущее отставание выработки на ж.д. перевозках от средней по экономике (рис. 6).

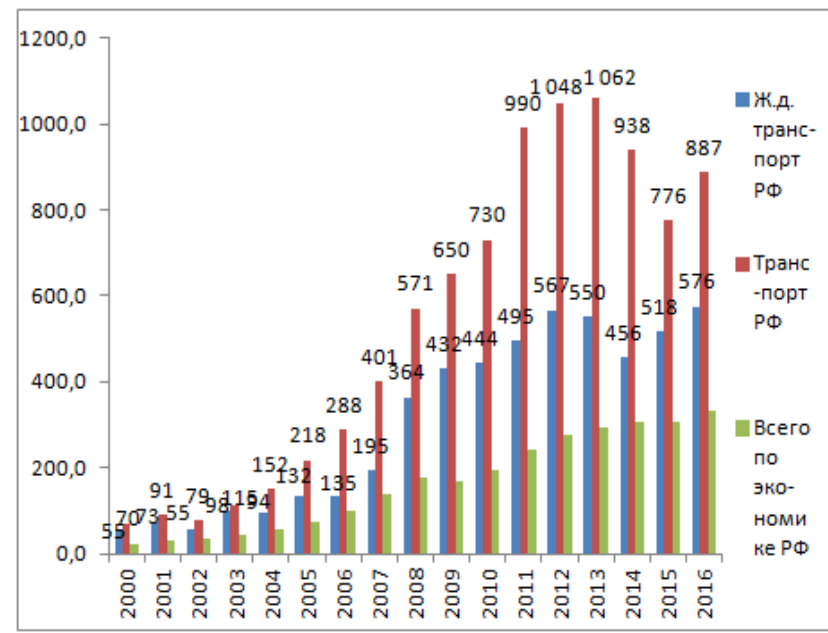

Puc. 3. Динамика инвестиций в основной капитал на 1 работающего в действующих ценах, тыс. руб.

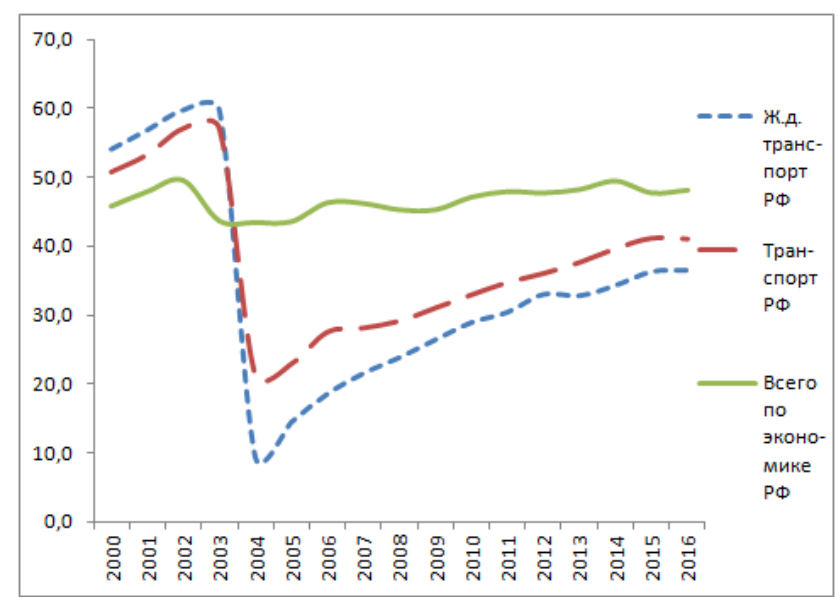

Puc. 5. Динамика износа основных фондов,\% 


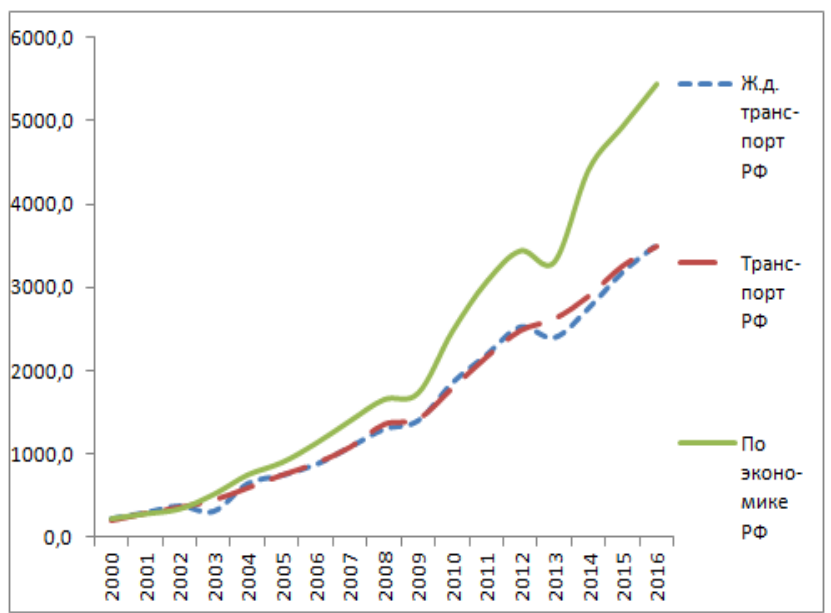

Рuc. 6. Динамика выработки - выручки на 1 работа ющего в действующих ценах, тыс. руб./человека

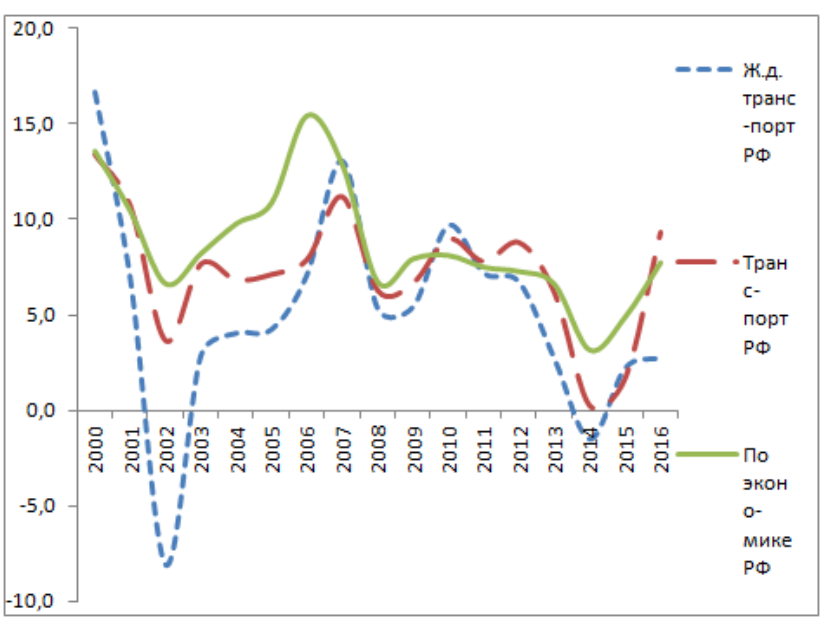

Puc. 7. Динамика рентабельности продаж по чистой прибыли,\%

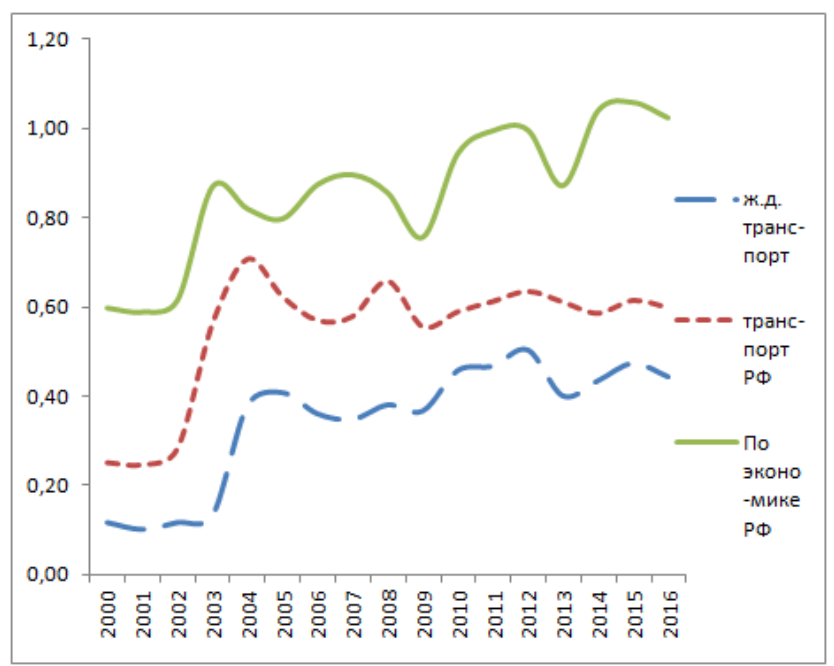

Puc. 8. Динамика показателя фондоотдачи, руб./руб.

Отдача основных фондов остается одной из самых низких среди других отраслей экономики (рис. 8). Как следствие, ограничивается обновление фондов по причине недостатка собственных средств, обусловленного низкими оборотами на рубль фондов.

Близкое к устойчивому можно охарактеризовать социальное положение отрасли. Подготовка кадров для транспортной отрасли устойчива; выпуск специалистов по сравнению с началом 2000-х годов, по данным статистики, утроился (рис. 9). Средний уровень заработной платы выше российского и отраслевого. С 2014 года он сокращается, но остается в целом высоким (рис. 10).

Вектор экологической устойчивости железнодорожного транспорта не однозначный. Наблюдаются отдельные улучшения: например, сокращается объем образованных отходов (рис.
12). С другой стороны, на фоне значительного сокращения выбросов загрязняющих атмосферу веществ по стране, по транспорту пропорционального сокращения не наблюдается (рис. 11).

\section{Заключение}

Выполненные по приведенной выше методике расчеты позволили заключить, что развитие железнодорожного транспорта остается устойчивым (2001-2004 гг.), а также близком кустойчивому (2005-2016 гг.) - таблица 2. Главной причиной снижения интегрального показателя выступает снижение индекса устойчивости в области экономических показателей. K 2016 году значение индекса по группе «Экономическая устойчивость» оказалось самым низким за рассмотренный период $(0,553)$. Социальная и экологическая устойчивость сохраняются на высоком уровне 


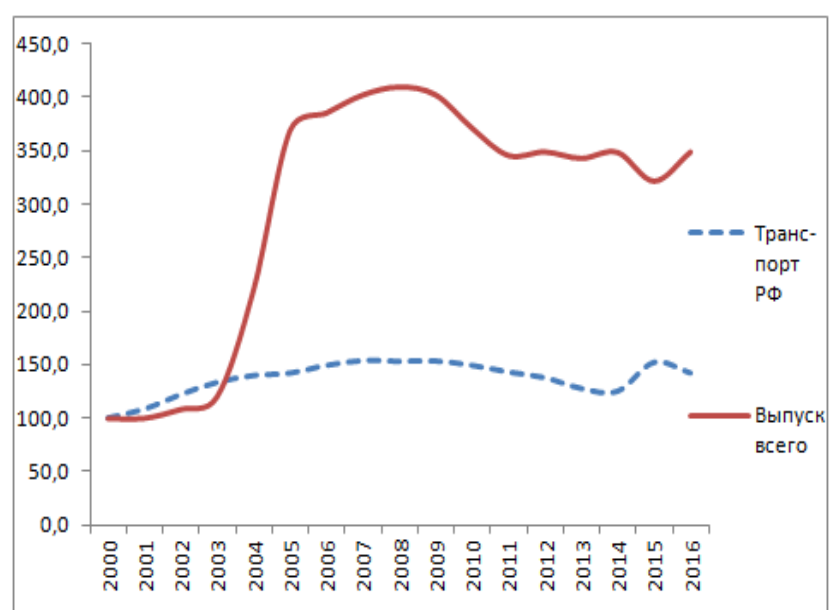

Puc. 9. Динамика числа выпущенных специалистов государственными и муниципальными вузами и учреждениями СПО (2000 г. = 100\%)

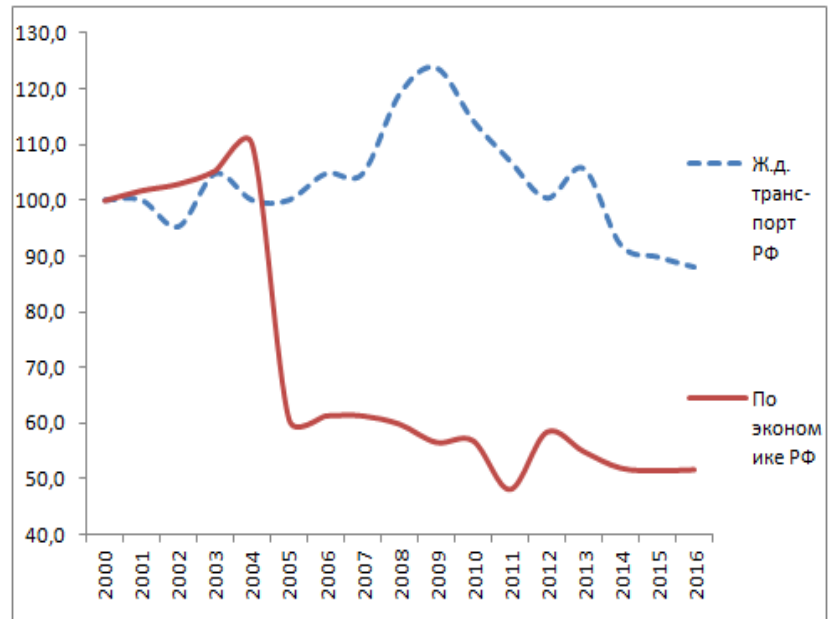

Puc. 11. Динамика выбросов в атмосферу загрязняющих веществ (2000 г. = 100\%)

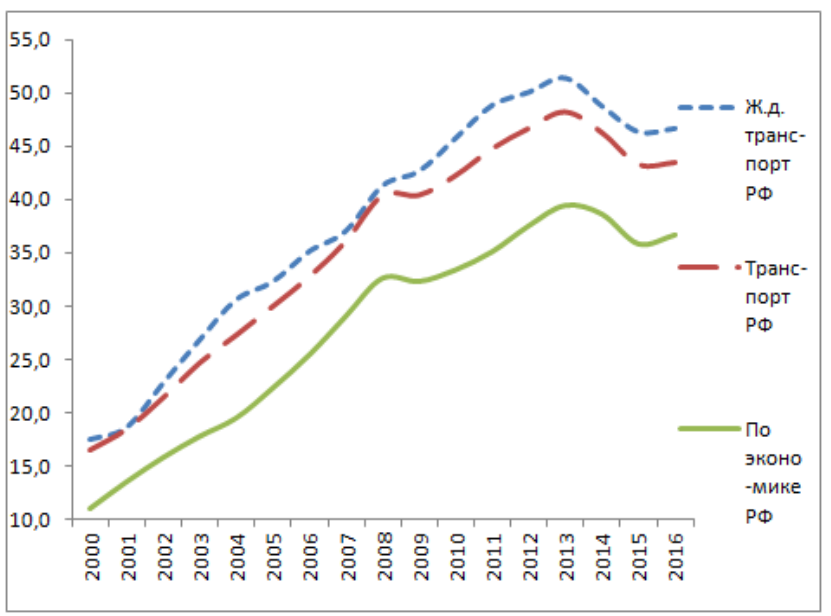

Рuc. 10. Динамика среднемесячной заработной платы работников, тыс. руб. (в сопоставимых ценах 2016 г.)

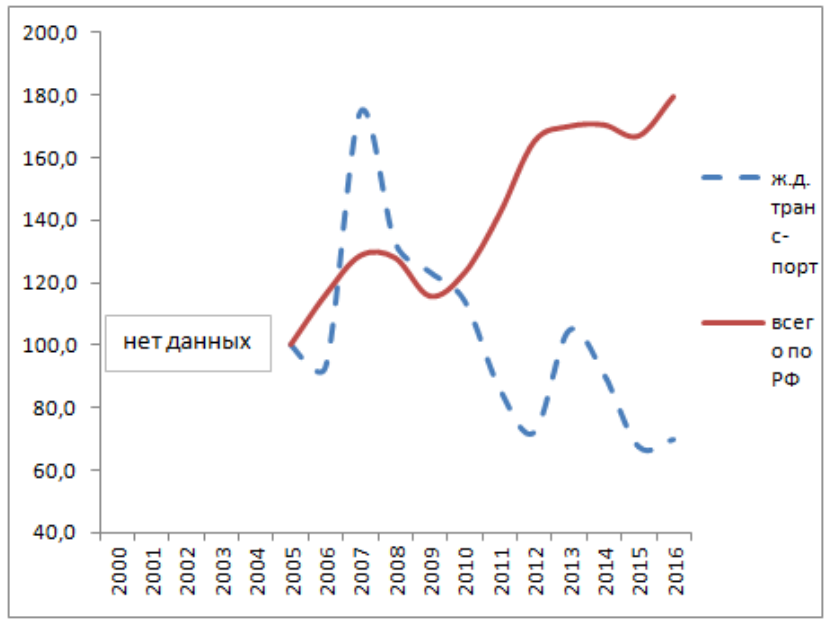

Puc. 12. Динамика образования отходов (2000 г. = $100 \%)$

Таблица 2. Результаты расчетов интегрального индекса устойчивости железнодорожного транспорта в 2001-2016 гг.

\begin{tabular}{|c|c|c|c|c|}
\hline \multirow{2}{*}{ Показатель } & \multicolumn{4}{|c|}{ Периоды - годы } \\
\cline { 2 - 5 } & $2001-2004$ & $2005-2008$ & $2009-2012$ & $2013-2016$ \\
\hline значение интегрального индекса устойчивости & 0,768 & 0,731 & 0,726 & 0,678 \\
\hline
\end{tabular}

на протяжении всего периода исследования.

В качестве рекомендаций по повышению экономической устойчивости предлагается использование преимуществ и наращивание эффекта от применения цифровых технологий в деятельности Российских железных дорог. Главный результат такой работы - удовлетворение потребностей пассажиров и грузо- отправителей на новом качественном уровне. За счет усовершенствованного сервиса для клиентов, эксплуатации железнодорожной информации-цифры, снижения операционных издержек будет обеспечено генерирование новых потоков поступления доходов. А на этой основе - поступательное движение по траектории устойчивости. 


\section{Библиографический список}

1. Абалкин Л.И. Экономическая безопасность России: угрозы и их отражение / Абалкин Л. И. // Вопросы экономики. - 2008. - № 12.

2. Журавлева Н.А. Устойчивое развитие железнодорожного транспорта: взгляд в будущее / Журавлёва Н.А. // Развитие экономической науки на транспорте: устойчивость развития железнодорожного транспорта: сб-к докл. IV междунар. науч.-практ. конф.-Киров: МЦНИИП, 2016. - 510с.- С.162-170.

3. Салихов А.Р. Устойчивое развитие и качество экономического роста / Салихов А.Р. // Экономические науки. - 2008. - № 48.- С.30.

4. Транспорт в России. 2018: стат. сб. / Росстат.- М., 2018.-101 с.

5. Ускова Т.В. Управление устойчивым развитием региона: монография / Т.В. Ускова.- Вологда: ИСЭРТ РАН, 2009. - 355 c. 